\title{
Too Scared to Teach: Secondary Students' Insights into Educators Silencing and Stigmatizing Gender and Sexual Diversity in Public Schools in Alberta, Canada
}

\author{
Tanya Surette \\ Acadia University \\ tanya.surette@acadiau.ca
}

\begin{abstract}
Despite a growing awareness of the disparities experienced by gender and sexual minority students related to academic attainment and well-being, some teachers continue to avoid discussing gender and sexual diversity. Through the use of narrative inquiry, this study captured the experiences of six secondary students in Alberta pertaining to the general absence of discussions of gender and sexual diversity and the misinformed way this controversial topic was being handled at school. These students attributed their teachers' silence to fear, being uneducated, and apathy. Through encountering the student narratives, implications for teachers aspiring to create inclusive learning spaces for this population are shared.
\end{abstract}

\section{Introduction}

The first national climate survey exploring the experiences of gender and sexual minority (i.e., gay, lesbian, bisexual, transgender, and queer) students in Canada, Every Class in Every School, was published in 2011 and revealed $70 \%$ of students continued to hear homophobic remarks daily, with the majority of sexual and gender minority students continuing to experience ongoing verbal, physical, and sexual harassment at school (Taylor \& Peter, 2011). Gender and sexual minorities experience perpetually higher rates of psychological distress, and this difference is almost exclusively the result of culturally maintained stigma, discrimination, and victimization (Callaghan, 2009, 2016; Crowell, Galliher, Dehlin, \& Bradshaw, 2015; Meyer, 2003). Despite an awareness of the oppression experienced by sexual and gender minority students, many public school educators acknowledge they routinely avoid discussing gender and sexual diversity in their classrooms out of a fear of reprimand (Leonardi \& Saenz, 2014; Puchner \& Klein, 2011; Sieben \& Wallowitz, 2009). When teachers avoid content inclusive of sexual diversity, heterosexuality remains privileged as the norm, further undermining the emotional and developmental needs of sexual and gender minority students (Macgillivray, 2000; Puchner \& Klein, 2011).

Much of the research in this field to date has captured the experiences of sexual and gender minority youth in the United States, with fewer studies documenting the experiences of students in Canada. At present, there are few studies exploring the impact of curriculum materials on gender and sexual minority students within non-denominational schools (Depoian, 2009; Kosciw, Greytak, \& Bartkiewicz, 2014), many of which rely on larger quantitative studies, and where few have explored the lived experiences of gender and sexual minority students. This 
research was unique in that it brought to the forefront the narrative accounts of Canadian students currently navigating the heterosexist environment in their schools, and offered insights into how students interpret the silence of their teachers. This opened up possibilities for educators interested in creating safer and inclusive learning environments. As a heterosexual cisgender female, I come to this research as an accomplice (Clemens, 2017) to the gender and sexual minority community. As a result, this study is focused on challenging structures that oppress gender and sexual minority groups through the maintenance of systematic heteronormativity.

\section{Literature Review}

A number of curriculum scholars have highlighted the inclusion of topics related to sexuality and gender remains rare and, when present, the information is often missing important contextualization and is therefore taught in incorrect, unbalanced, and harmful ways (Macgillivray, 2000; Meyer, 2009). In discussions pertaining to sexual health, homosexuality often still remains taboo (Zimmerman, 2015), and when it is covered, is generally related to risktaking behaviours and in the context of AIDS or as a pathology, thus maintaining damaging stereotypes (Friend, 1993; MacGillivray, 2000; Meyer, 2009; Puchner \& Klein, 2011). The result is that many students are either uneducated or mis-educated on topics related to gender and sexual diversity, which impacts not only gender and sexual minority youth, but all students in their developing identity and beliefs. Ghiso, Campano, and Hall (2012) point out the integration of texts that are inclusive of gender and sexual diversity offer windows and mirrors for students to explore the world of diverse sexuality and gender identities and themselves, by connecting the complexities of diversity to their own lives, and the lives of their peers. The inclusion of these topics better prepares students to engage in a democratic society, where diversity is understood as normal, and can be celebrated.

Sieben \& Wallowitz (2009) argue no teaching is neutral, so creating classrooms free of discussion on controversial topics, such as gender and sexuality, does not situate the teacher as impartial or objective. In fact, a classroom devoid of such topics sends a clear message that the teacher regards the topics of gender and sexuality as forbidden, taboo, and ill-suited for children (Sieben \& Wallowitz, 2009). Robinson and Ferfolja (2002) found many teachers in training were resistant to including gay and lesbian concerns in their teaching, based on a belief that discussing sexual diversity was irrelevant to the schooling context. More recently, Meyer, Taylor, and Peter (2015) affirmed many teachers continue to resist approaching topics pertaining to gender and sexual diversity, in an attempt to avoid negative repercussions from administrators, parents, and community members. Avoiding the topic of gender and sexual diversity sends messages to gender and sexual minority students about their place and relevance in the school.

Although teachers have authority over students, many actors in a school community, such as administrators and policy makers, have power over teachers. As previously discussed, many teachers routinely omit or avoid topics pertaining to sexual and gender diversity in their class; however, research has supported that this operates more at a systemic level than an individual one. In their qualitative study involving interviews with sixteen educators, Fredman, Schultz, and Hoffman (2015) found teachers avoided topics of homosexuality primarily out of fear of 
backlash. Their study demonstrated the apprehension of educators about administrative responses as well as repercussion from the community, and parents.

Language is another way teachers may silence and stigmatize gender and sexual minority students. Teachers commonly perpetuate heteronormativity, which is the privileging of heterosexuality and the normative expressions of male and female genders. This occurs through how teachers talk about (or avoid the topic of) sexual and gender diversity in class (Puchner \& Klein, 2011). In their quantitative study involving over 7000 students, Kosciw, Greytak, Diaz, and Bartkiewicz (2010) found students reported teachers actively repeated harmful messages and blocked students' attempts to disrupt dominant discourses pertaining to heteronormativity, reporting $50 \%$ of transgender students heard teachers or staff make negative comments about their gender expression, 33\% of students heard school staff make homophobic, sexist, or otherwise negative remarks about someone's gender expression in the past year, and $47 \%$ of the time, school staff did not intervene after witnessing abuse of students based on their gender or sexuality presentation. When heterosexist attitudes towards sexual and gender diverse students are not challenged or are reinforced, homophobia and transphobia are not only tolerated, but normalized and justified (Leonardi \& Saenz, 2014; Swearer et al., 2008).

Miller and Gilligan (2014) argued the absence of curriculum materials and policies directly addressing the inclusion of gender and sexually diverse youth act as microaggressions, which continue to alienate this population of students. Castro and Sujak (2014) identified that through gay-inclusive curriculum, spreading messages about knowledge, empathy, and acceptance could reduce internalized homophobia, stigmatization, discrimination, and violence. In their quantitative sample of over 7000 students, Birkett, Espelage, and Koenig (2009) found that the inclusion of themes and discussions pertaining to sexual diversity resulted in a positive school climate for gender and sexual minority students, and reduced negative outcomes. For schools to become safe and welcoming for all students, homophobia and transphobia, heterosexism, heteronormativity, and heterosexual privilege must be explicitly addressed and interrupted in students' learning, which requires a movement beyond the focus on individual acts of aggression and microaggressions, to the system that maintains this dominant discourse (Airton, 2009; Macintosh, 2007; Nunn \& Bolt, 2015).

Fredman et al. (2015) point out students are the audience most receptive to the importance and relevance of addressing sexual and gender diverse topics in school, but their voices are primarily unrepresented in the research. For this reason, narrative inquiry was employed for this study in an effort to capture the lived experiences of current students. Aligned with Clandinin and Rosiek's (2007) notion of narrative inquiry, the individuals' lived experiences are privileged as sources of insights, useful beyond the individual themselves and pertinent to the larger field of social science scholarship. The following narrative accounts are considered valuable in the insights they have to offer about the current realities of some students navigating heteronormativity in their schools.

\section{Methods}

The present study was a multi-method qualitative inquiry involving narrative interviewing with secondary students. This study received research ethics approval from the University Conjoint 
Faculties Research Ethics Board. The focus of this article is on the analysis of narrative interviews as they pertained to student perspectives on their teachers' omission or misinformed discussions of topics and issues relating to gender and sexual diversity. Narrative inquiry, which considers experience to be the fundamental ontological category from which all inquiry proceeds, was employed for this study (Clandinin \& Connelly, 2000; Clandinin \& Rosiek, 2007). Narrative inquiry values lived experiences as the ultimate source of validation for knowledge (Clandinin \& Rosiek, 2007). This study was primarily concerned with capturing the lived experiences of students, as they pertained to heterosexism and heteronormativity at school.

\section{Data Collection}

This study employed purposive sampling techniques (Maxwell, 1997). The population of interest for this study was secondary students, between the grades of nine through twelve, currently attending a public non-denominational school in rural Southern Alberta. Two separate school divisions granted access to their student population for recruitment for this study. Within these two divisions, seven schools were requested, and of those seven schools, five administrators agreed to have their school participate. Two administrators declined participation out of fear of backlash from parents and the community. Students of all gender and sexualities were invited to participate but participation required signed parental consent, which was a requirement of the school divisions and a practice aligned with the best practices for research involving partially dependent persons (Canadian Psychological Association, 2017). Recruitment involved all teachers reading a recruitment script to the entire class at the same time on a selected day. This ensured all students present that day received the same information and had equal access to participate. Posters were put up around the school, many in confidential locations and in counselors' offices, and students were encouraged to contact the researcher directly. Six participants contacted me and met the criteria for participation: being a grade nine through twelve student, having signed parental consent, and participant assent to participate, and being willing to engage in at least one open-ended narrative interview.

At first contact, students were provided with parental consent forms and participant assent forms, which included a summary of the study, possible risks and benefits to their participation, their rights as participants, and information pertaining to the handling and storage of their personal information. This information was also reviewed with each participant at the onset of the first interview. Upon conclusion of the first interview, participants were provided with a list of community resources to access should they require additional support or services. The six participants ranged in age from 14 to 17 years-old. Two participants were transgender, one male (Jayce) and one female (Dana), and four were cisgender, female (Rosie, Elisabeth, Nicole, and Hunter). Regarding sexuality, two participants identified as bisexual (Elisabeth and Nicole), two as pansexual (Jayce and Dana), one as queer (Hunter), and one as heterosexual and an ally (Rosie).

Students were invited to participate in multiple one-to-one, open-ended interviews. Interviews were kept invitational and participant-led, and aimed for rich, nuanced, storied samples of subjectivity to discover how it has felt to live the life the participants have had in relation to living within a heteronormative school environment (Josselson, 2013). The interviews began with a series of warm-up questions which asked about students' experiences, in their personal life and the media, with individuals who identified as a diverse gender or sexuality. Next, 
definitions were sought from each participant for key terms (i.e., gender minority, gay, lesbian, cisgender, etc.) to ensure the same definitions of key terminology were used and so the participants' language could be mirrored in the interview and captured in the narrative accounts. Participants were asked what their beliefs were about the rights of individuals who were gender and sexually diverse. Lastly, the interview was opened up by asking students to comment on specific instances at school that either supported or interfered with equal rights for students who are gender or sexually diverse. Each student brought to the interview a different history and interpretation of the questions and thus each interview took a different direction.

After the first interview, students were invited to participate in a second interview, and all six accepted the invitation. Each participant was encouraged to keep a log of anything of interest that came up or things they thought about after the end of the initial interview. Five of the six students participated in a second interview, with two of the participants requesting a third interview. A total of 13 interviews were conducted, totalling 12.3 interview hours. All interviews were audio recorded digitally and transcribed verbatim (Maxwell, 2005). All students were asked to select a pseudonym and this replaced their name on all transcripts. These pseudonyms were used to share specific quotes of the research participants while protecting their confidentiality.

Qualitative research relies on various criteria for evaluating the trustworthiness and credibility of the findings (Lincoln \& Guba, 1985; Bloomberg \& Volpe, 2012). Lincoln and Guba (1985) proposed the criteria for evaluating the trustworthiness of a qualitative study involves credibility, dependability, and transferability. To increase the credibility, dependability, and transferability of this study, I relied on member checking (Merriam, 2002), triangulation of data (Merriam, 2002; Cohen, Manion, \& Morrison, 2011), and self-reflexive writing (Clandinin \& Connelly, 2000; Josselson, 2013) to watch my own assumptions and reactions throughout the interview process. The initial analysis involved creating narrative vignettes, which provided a storied account of the interviews and weaved together verbatim quotes in a chronological order of events. These vignettes were returned to the participants for member checking to ensure accuracy of their accounts and in an effort to avoid over-interpretation of their stories. Participants were given the opportunity to add, delete, or adjust anything in the narrative vignettes.

\section{Data Analysis}

The data analysis of narrative research involves interpretation, which inevitably is the result of what the researcher chooses to attend to when reading and re-reading the narrative accounts. Thus, at every stage of the analysis, narrative research is always interpretive, as the narrative researcher is not separate from or outside of the text (Josselson, 2006 ; Kim, 2016). The narrative interviews were read and re-read through the lens of heteronormativity and heterosexism. However, aligned with Kim's (2016) notion of flirtation, I returned to the transcripts multiple times during the data analysis stage, looking for new, surprising, and unique findings that highlighted moments of hope, insights, and opportunities for change.

The results shared in this article were obtained through analysis of narratives. Analysis of narratives, also called the paradigmatic mode of analysis, attempts to fit individual details into a larger pattern (Kim, 2016). Through this analysis, common themes were discovered and organized under several categories using stories as data (Kim, 2016). Analysis of narrative was utilized to arrange the data around common themes across the collected stories (Kim, 2016;

Journal of Contemporary Issues in Education, 2019, 14(2), pp. 33-49. 
Polkinghorne, 1995). Interview transcripts were uploaded to a computer-assisted qualitative data analysis program, NVivo, for more ease of sorting and coding the substantial amount of interview data. Thematic categories were found and refined for shared experiences across participants, as well as repeated encounters of heteronormativity within and between narratives, and unique observations and experiences within individual accounts (Owen, 1984). Following the primary coding, secondary coding involved re-reading transcripts to further refine, combine, and elaborate upon the themes identified in the first phase of coding, and organizing the results into subthemes. In keeping with constant comparison encouraged in the process of thematic analysis, relevant literature informed the coding and analysis continuously throughout this analysis phase (Charmaz, 2000).

\section{Results}

It was a unanimous assertion from each participant in the study that topics and issues pertaining to gender and sexual diversity remained almost completely absent from classroom discussions. This has already been well established by previous research. Discussed here are the unique findings that (a) students unanimously felt this eradication of gender and sexual diversity from the classroom was pervasive and intentional; (b) when gender and sexual diversity did come up, it was quickly shut down, or harmful messages were sent by teachers; and (c) students had alarming insights as to why their teachers avoided or were misguided in their conversations around gender and sexual diversity. These findings will be discussed below and supported through participants' quotes to bring the voices of the perceptive youth who shared their stories to the forefront.

\section{Keeping Gender and Sexual Diversity in the Closet}

Each participant was eager to engage in our interviews, all commenting on how rare it was to have the opportunity to talk to an adult about the topic of gender and sexuality. In fact, Dana, Hunter, Nicole, and Elisabeth all shared that the first time they heard a teacher talk about gender and sexual diversity was when the advertisement for this study was read in class. Elisabeth, a grade nine cisgender female, recalled her reaction to hearing about the study:

There's never been a time other than when my teacher brought up the poster thing for this. That really got my attention. I was like, this is odd. I even looked over at some of the more conservative people in my class and I could just see their face, and I was like really, they literally haven't even gotten into it and you're already dismissing it. Elisabeth's reaction, which was shared by three other participants, not only highlights how these topics are often excluded from the classroom, but also the sense that they were quickly dismissed as unworthy or inappropriate, as observed by the reactions of their peers. These four participants also noted the advertisement for the study caught them off-guard because it was rare that this conversation comes up in class. The participants weren't the only ones caught off guard from the advertisements for this study. Hunter, a grade 12 cisgender female, shared dismay at how her peers handled the posters put up for this study:

Somebody had posted on their Snapchat that they had taken one of the pieces of paper that had all of your information on it and they put it in the toilet and tried to flush it. So somebody else went into the guys' bathroom I guess and saw it in the toilet and took a picture and snapped about it everywhere. I can't even imagine how the people in our 
school who are part of that community feel. I'm just really disappointed to see people doing those kinds of things.

The reaction of Hunter's classmates to the advertisement for this study illustrates the strength of heteronormativity in her school and how students are not used to being provided opportunities to explore this area of diversity. Every participant identified sexual education as a natural place for these conversations to emerge, yet even in this setting, gender and sexual diversity was omitted.

After clearly establishing gender and sexual diversity was not discussed in sexual education or anywhere else in the curriculum, I asked the participants what the class covered, and each participant similarly responded that sexual education solely addressed abstinence, how not to get pregnant, and sexually transmitted infections (STIs). Rosie, a grade 10 cisgender female, observed that sexual education was taught from the assumption that sex was heterosexual. Hunter discussed dismay that the sexual education curriculum had not even acknowledged that "sex can be a good thing" and shared the belief that the only reason schools taught sex was to discourage kids from having it, so they could avoid getting pregnant. When participants discussed their general experiences within sexual education, there was a common sentiment that it was failing to equip students with information about readiness for sex, diversity in sexuality, and resources for safe sex practices. Students all shared pregnancy prevention as the primary focus of sexual education in their schools, which Elisabeth acknowledged was an important part of the conversation but reminded "sex is obviously not one thing."

Some participants mentioned times when there was an opportunity to discuss gender and sexual diversity, but the topic was avoided or shut down. Dana, a grade nine transgender female, felt disappointed in her grade eight sexual education class when her teacher could not answer a question about gender and sexual diversity that was put in an anonymous question box:

The teacher even did this thing last year where you could put in anonymous questions in this box. I knew more than one person put in a question about gender or talk about sexuality and she never did. I know the teacher wasn't against it but I feel like, why? What is the issue answering those questions?

Dana's observation not only captures an instance of her teacher intentionally avoiding the topic, but also a strong message, inadvertently or not, to the student who posed the question and other equally curious students, that gender and sexual diversity aren't legitimate topics and do not belong in classroom discussions around sexual education. Elisabeth also recalled questions being asked directly in sex-ed class related to gender and sexual diversity, and the discussion being quickly glossed over or avoided. Through their recollections of their sexuality instruction, and education in general, the participants did not believe the absence of gender and sexual diversity from the classroom was coincidental.

\section{Harm of Misinformed Conversations}

Other moments captured in the interviews highlight rigidity from some teachers who interrupted teachable moments where students themselves tried to authentically bring up topics of gender and sexual diversity. Rosie described an encounter in her drama class:

A couple of weeks ago we were in drama and trying to come up with roles for the people on stage and we're like 'okay these people are father and son' and one boy said 'poncho's my husband' and we were like, 'oh yah, okay' and the teacher was like, 'no you're not allowed to portray gay relationships or homosexuality because someone might take it too

Journal of Contemporary Issues in Education, 2019, 14(2), pp. 33-49. 
far,' and she said the things she didn't allow in her class were portraying drug abuse or substance abuse, gay relationships, or things that make people uncomfortable. She didn't allow those. She said someone might take it too far and it could get to a weird place. But it could get to a weird place with straight relationships and people; students are allowed to portray that on stage.

Rosie also shared an instance in social studies where her teacher engaged the class in a discussion of current events and brought in articles for the students to read and to provide a commentary on. Rosie's teacher brought in several articles, two of which were on gender and sexual diversity. While excited at first to see these articles included in the assignment, she was subsequently disappointed to find they both took a particular stance on the topic. The first article was from CBS News titled, "Should drag shows be used as a teacher tool in Alberta schools" (Huncar, 2016). The primary focus of the article was on backlash over the educational toolkit from critics, who called for a more balanced resource for all views. The second article, from The National Post, titled 'Rex Murphy: Jordan Peterson - A real professor, at last.' This article covered the story of a University of Toronto professor who refused to use ersatz pronouns for students who identify as a gender minority. Murphy calls Peterson, "A brave man. Better, he is an actual, a real, university professor. May his stamina and courage hold. Parents, send your children to his classes." (Murphy, 2016). Rosie expressed concern with the one-sided nature of articles and the lack of discussion:

They were biased quite a lot. They were both of the same viewpoint and were pretty scathing, actually. My teacher particularly didn't maybe do a great job of showing different viewpoints in the class. He always made a point of saying, 'oh go research for yourself', but then the only content he showed in class was a certain viewpoint. Rosie's recollection of her social studies project highlights the problematic nature of some teachers' attempts to engage in discussions around gender and sexual diversity when not providing curriculum grounded in anti-oppressive education. What was additionally problematic about this example was, as Rosie noted, none of the articles pertaining to gender and sexual diversity were debriefed, discussed, or contextualized in class, leaving students to take them at face value. In another example, Nicole, a grade nine cisgender female, recalled an instance when her science teacher's discussion of genetic diversity and his use of language came across in a way that she perceived was inconsiderate towards gender diverse students:

Our teacher was talking about types of spectrums for genetics, where you can be tall or you can be short, and that's a spectrum. But one of them he kept referring to as gender. It's your gender. And I kept sitting there like, I know you're the teacher and it's probably not what you want to think, and it's probably not what you think, but in my opinion, gender is not a finite thing.

It can be surmised Nicole's teacher's approach of this topic did not intend malice; however, without considering the gender diversity or fluidity in his class, it was a microaggression that alienated students. Nicole discussed another incident:

The social teacher showed a picture of the Berlin wall and there's two guys that are kissing and it was a big thing and the teacher prefaced it and said, 'now I know this is gross, and it was protested, but they weren't actually gay, it was just a political statement.' But even if it was, why do you need to say that? They're putting a trigger warning in front of it. They're saying that it is something that is offensive.

Nicole's recollection illustrated a missed teachable moment, where an educator overlooked an opportunity to interrupt the homophobic reactions of students and challenge the heteronormative

Journal of Contemporary Issues in Education, 2019, 14(2), pp. 33-49. 
discourse that encourages these reactions. Each of these examples highlight some educators pervasively and intentionally avoid topics of gender and sexual diversity a majority of the time, and when they do permit their presence, it is haphazardly, which appears to further oppress and marginalize and, arguably, promotes discriminatory attitudes and beliefs towards diverse gender and sexual identities, rather than interrupting them.

\section{Why is my Teacher Too Timid to Teach about my Identity?}

It has been disheartening to hear participants consistently recounting stories where gender and sexual diversity was minimized, discounted, stigmatized, and absent entirely from their educational experiences. However, an interesting aspect of the discussion was speculation as to why their teachers were or were not addressing this topic, and three principal reasons were identified by participants. The first was out of fear; the second reason was being uneducated themselves, and the third reason was they felt teachers were taking the easy way out.

Fear. A positive finding from the participants' narratives was they believed many of their teachers were allies. Dana and Elisabeth both felt it wasn't because their teachers didn't care or were not supportive that they were not discussing these topics. Dana identified a belief that most of her teachers were "not against it, but they just don't say anything." Elisabeth also shared her positive impressions of her teachers:

The faculty here just don't seem like the kind of people who are, you know, against it. I know some teachers are very trusting and you can just get a sense when people are more open minded than others. I think a lot of teachers have grown up to try to be accepting of everything; I mean they're teachers right?

Jayce, a grade 11 transgender male, and Nicole also had positive experiences and share the sentiment that their teachers are caring and safe to talk to, and some worked to create safe learning environments. Despite this sentiment, a number of the participants had a keen awareness of the pressures teachers face that interfere with their intentions. Many participants acknowledged teachers were part of a complex system that places constraints on what they teach and how they conduct themselves. Several participants discussed the pressures on teachers to conform to the norms of the surrounding community, instilling a sense of fear about straying from the curriculum. The dominating concern in this context was a fear of parents. Several participants commented teachers could potentially get into trouble from parents or from administration if they approached the topic, through parents getting upset at them and/or their administrator not supporting their decision to include these topics. This is supported by Meyer, Taylor, and Peter (2015)'s study, which explored teachers' fear of parental backlash and limited administration support as two primary reasons for the persistent silencing of these topics. Dana shared her perspective on the issue:

I think there's kids in the class who would go home and be like, Ms. G was shoving gay stuff down our throats in class, and she would get into trouble or something.

Rosie shared a similar belief, which she understood first-hand. Both her parents are teachers, and she grew up seeing the risk when students complained about their teachers at home, resulting in reprimands for the teacher:

I think they don't want to talk about it or let students talk about it because someone is going to go home and tell their parents about it and then the teacher is going to get in trouble. I don't think I've ever encountered any teachers that are explicitly homophobic, 
but there are a lot that could possibly be in support, but they don't want to get into trouble, so they don't say anything.

Participants agreed their teachers allowing the fear of backlash to justify the avoidance of gender and sexual diversity discussions in the classroom highlights a problem at the administrative level. This was the most prevalent reasons discussed across the narrative interviews as to why these students felt their teachers avoided this topic. This raises some important issues about how educators are failing to teach students to have difficult conversations and consider controversial topics in an informed and democratic way. Alberta Learning guidelines assert that studying controversial topics is essential in preparing students to responsibly participate in a democratic and pluralistic society, while building on logical reasoning skills, open-mindedness, and respect for different perspectives (Alberta Learning, 2002; 2002b). The narratives illustrate these students adeptly noticed the fear of their educators regarding these topics.

Uneducated Educators. The second reason students believed their teachers were not able to engage in discussions around gender and sexual diversity is that they lacked education and training themselves. Students demonstrated a keen awareness that those adults entrusted with their education may not be trained or equipped with tools to even attempt addressing the topic at all. Elisabeth articulated this belief concisely:

It's weird to see them not know how to handle it and just brush it off. I think a lot of it goes back to how teachers are trained to teach because, you know, you can only do what you're taught how to do. If you don't know how to do something, obviously you don't know how to do it. So, I guess if teachers aren't taught to address these issues, then, you know, especially if it's controversial, you have to be careful what you say because you can be in deep water.

Dana also identified an awareness that teachers lacked training in this area and that they were not kept up to date on the changes happening in schools, leaving them unprepared:

They don't say anything out of not caring. They just don't know how. It would be great if every teacher had to go to a workshop or something that would have educated them on it. Without proper training and preparation, the topic of gender and sexual diversity may be too intimidating or uncertain to invite into classrooms. Dykes and Delport (2018) highlighted institutional heteronormativity in higher education continues to act as a barrier to pre-service teacher training in cultural responsiveness in terms of gender and sexual diversity, with only two of their 10 participants receiving any sexual diversity training in their degree program. As the narratives highlight above, students notice the effects of this lack of training in their teachers' incompetence with appropriately addressing these topics.

Easier not to. The final attribution the participants made to why their teachers were removing topics of gender and sexual diversity from the classroom was that it wasn't worth the effort. Participants felt it was easier for teachers to maintain the status quo and eliminate unnecessary stress and tension in the classroom, or for themselves. Elisabeth shared her thoughts on why teachers were not addressing the topic in class:

I'm going to be honest, as a teacher, what's easier? Just using the typical Jennie and Tom or you know the more controversial one? Especially if you just want to teach the class or just want to get it done. As a teacher, and I understand as a teacher it may be easier just to, you know, think it's only health. It's not a main course, so why try to bring anything, you know, difficult up I guess. I get that. It's a long day, you know, I do understand. It's 
not the easier choice, but it's also damaging to an extent when it's not being talked about.

So, it's just thinking about well this is easier, but what is more beneficial?

Elisabeth's observation about teachers not taking their role in sexual education seriously is problematic in that it may promote students not taking the topic seriously either. Hunter and Dana were also aware their teachers had a lot to get through in a day, and a difficult or controversial topic was probably more work or effort than their teacher wanted to put in.

The participants' comments illustrated students have a general fondness of their teachers and are sympathetic to their teachers' inabilities or hesitations to bring up these topics. However, they also clearly exposed that, while their teachers could escape repercussions and uncomfortable moments in the classroom, this practice of avoidance had serious consequences for gender and sexually diverse students, as well as the general student population. When taking into consideration Suldo et al.'s (2009) findings that students' perceptions of how often their teachers cared for them and treated them was most related to students' overall life satisfaction, it is problematic to discover the students in this study did not perceive their teachers as willing to put in the extra effort to demonstrate care and protection of their identity and inclusion. This negative perception runs the risk of fracturing the positive impact of teacher support on students' emotional well-being.

\section{Discussion}

Students will spend more waking hours at school than anywhere else during their early developmental years. Teachers are entrusted with not only their care and education of facts, but also have a critical influence on their values and beliefs about themselves and others. In light of this, the results of this study are alarming to consider the participants perceive these important figures and role models as fearful, uneducated, and/or unwilling to spend the energy to engage in topics that are difficult. The participants in this study unanimously perceived the eradication of gender and sexual diversity was intentional and pervasive across subjects and all their years of schooling. What the participant narratives highlight is that the silencing that occurs when their teachers routinely omit any content inclusive of gender and sexual diversity, or discuss it in a cautious or harmful manner, contributes to the heteronormative discourse operating in their schools and possibly perpetuates the homophobic and transphobic attitudes, behaviors, and comments of the student body. Teacher avoidance of the topic not only sends the message that discussions of gender and sexual diversity do not belong in school, but gender and sexual minority students do not either. This affirms Sieben and Wallowitz's (2009) position that the more educators safeguard the classroom from topics such as sexual diversity, the more students - for whom school seems foreign, hostile, or irrelevant — are silenced.

A hopeful finding from this study was that most of the students sincerely believed their teachers cared about the well-being of students. However, many of them also noted they didn't believe their teachers had the tools or education themselves, or support from their administration, to address these topics effectively. Aragon et al. (2014) suggest meaningful teacher training moves beyond workshops and professional development activities and must begin with an internal reflection and examination on teachers' own attitudes towards LGBTQ students, and opening themselves up to the possibility they themselves may be contributing to creating and perpetuating homophobia and transphobia in their schools. Grace (2006) concurs that teachers

Journal of Contemporary Issues in Education, 2019, 14(2), pp. 33-49. 
must first study their own lives, and the intersection of their personal values and beliefs and their professional practice, to better understand how they profoundly impact students' lives and learning. For teachers who are invested in creating safe and inclusive school environments, a starting place is to begin exploring and challenging their own normative notions of gender and sexuality and critically exploring the way their classroom discussions, lectures, lesson plans, curriculum outlines, and interactions may perpetuate heterosexism in their classroom.

It is critical to underscore that it is unfair to place all of the ownership and blame on classroom teachers, but rather, consider the system in which teachers operate and the level of support they perceive they have or would have to engage in these controversial conversations. This aligns with findings from Fredman et al. (2015) and Meyer, Taylor, and Peter (2015), that teachers may avoid this topic out of concern for a lack of administrative backing. Without these conversations from the top down, it is unreasonable to expect teachers to take a leap of faith and hope they will have administrative backing and support if they do open up the classroom space to these critical dialogues. For educational leaders, the implication here highlights the importance of seeking out appropriate and informed training opportunities for teachers, support staff, administrators, and senior administrators to better understand gender and sexual diversity and the needs of minority students. Relevant areas include understanding proper terminology and pronouns, safe-sex practices for gender and sexually diverse youth, current risk factors gender and sexual minority students face, opportunities for programs to bring into the school to incorporate inclusion, how to establish and support Gay Straight Alliances, how to establish and communicate safe bathroom and locker-room spaces, curriculum lessons and objectives that could invite discussions around gender and sexual diversity in a safe and respectful way, and how to be an ally to gender and sexually diverse students through action and reaction.

Each participant identified they felt the avoidance of the topic was one of the biggest barriers to creating schools that not only protected gender and sexual minority students from overt harassment, but shifted the ongoing discriminatory attitudes and behaviors of their peers. Without beginning to open these dialogues, the participants and their gender and sexually diverse peers continued to be forced to the margins and left discounted, while their heterosexual peers were permitted to continue to develop a strong normative bias towards heterosexuality and a negative perspective towards topics of diversity. Dana succinctly articulated the impact of this eradication on not just her emotional wellbeing but her basic ability to engage in her studies: Not feeling safe in the class, how do you learn when you feel like that? They do all this stuff like 'oh we're going to do this reading comprehension test' or 'we're going to do this and do that because we want to make sure you're really learning', or 'we're introducing a new way of math that's more hands-on and helps you learn' and it's like, as crappy as the old ways of doing things were, they would've been good enough if I could actually focus on learning at school.

The need to address this topic moves beyond educating around an important area of diversity but providing students with their basic right to an educational space that is conducive to learning. The suggestions provided by the participants demonstrated simple and small ways their teachers could begin to interrupt the heterosexism in their schools and open up a space for gender and sexual minority students to be validated. Each student expressed a plea to their teachers to talk about it, across the curriculum, starting from a young age, in a normalized way. Nicole had the following advice for her teachers:

Journal of Contemporary Issues in Education, 2019, 14(2), pp. 33-49. 
Talk about it. Even if it's not necessarily what you agree with. Even if you don't necessarily think gay or trans people, that they are or should be equal. You're in a public school. Stick up for those kids. Those kids are going to be beaten down and it's your job for them to not be beaten down because you're constantly toting how we're not supposed to bully each other in any form, but if you're not getting in there when you overhear some kid being mean to another kid because of how they dress, because of how they talk - and they're calling them gay or queer or whatever - then, you're not walking the walk that you're telling us to. So, just get out there and help those kids because you care about them. Why should who I am change that really?

\section{Limitations}

The participants in this study had important and relevant stories to share about their school experiences, although the sample size of six was small. There are two primary factors predicted to be the cause of the sparse self-identified participants. First, requiring parental consent limited participation to those students who could openly dialogue about the study with their parent(s). Secondly, the highly conservative nature of the communities and schools selected for this study likely resulted in many students not participating due to not being open about their diverse gender identity or sexual orientation. Moreover, the accounts captured in this research left out the narratives of teachers and other school personnel. As such, claims in this research are made based on student experiences and cannot be confirmed without further exploration into the experiences and attitudes of their educators. Additionally, this study was conducted in small rural towns in Southern Alberta, an area well known to be populated with individuals who are conservative in their values and beliefs. Students attending schools embedded in these communities may experience heteronormativity differently than students attending schools in more urban locations.

\section{Conclusions}

This research provided a unique opportunity to visit the lived experiences of those currently navigating heteronormativity and heterosexism in schools. Future research exploring the narratives of teachers, administrators, policy makers, and students within the same schools and divisions would be useful in contextualizing the larger system which influences what is included and what is omitted from the classroom. Additionally, further research with larger populations of gender and sexual minority students navigating rural and conservative school environments would be valuable in continuing to better understand how these systems may operate differently than schools within larger urban areas. While maintaining a heteronormative classroom may protect teachers from possible backlash, it prohibits them from creating the type of environments that foster learning, promote safety, and establish a model for respect and appreciation of diversity. This research opens up an important space for educators to reflect upon their own beliefs, training, and current practices and, for those interested in having an anti-oppressive educational practice, to find opportunities to grow and learn from these students' experiences.

\section{References}

Airton, L. (2009). From sexuality (gender) to gender (sexuality): The aims of anti-

Journal of Contemporary Issues in Education, 2019, 14(2), pp. 33-49. doi: 10.20355/jcie29367 ISSN 1718-4770

(c) Author(s), Creative Commons Attribution 4.0 (CC BY 4.0) licence

http://ejournals.library.ualberta.ca/index.php/JCIE 
homophobia education. Sex Education: Sexuality, Society, and Learning, 9(2), 129-139. http://dx.doi.org/10.1080/14681810902829505

Alberta Learning. (2002). Career and life management (Senior High). Alberta: Canada. Retrieved from https://education.alberta.ca/media/160199/calm.pdf

Alberta Learning. (2002b). Health and life skills kindergarten to grade 9. Alberta: Canada. Retrieved from https://education.alberta.ca/media/160196/health.pdf

Aragon, S. R., Poteat, V. P., Espelage, D. L., \& Koenig, B. W. (2014). The influence of peer victimization on educational outcomes for LGBTQ and non-LGBTQ high school students. Journal of LGBT Youth, 11(1), 1-19. http://dx.doi.org/10.1080/19361653.2014.840761

Birkett, M., Espelage, D. L., \& Koenig, B. (2009). LGB and questioning students in schools: The moderating effects of homophobic bullying and school climate on negative outcomes. Journal of Youth and Adolescence, 38, 989-1000. doi:10.1007/s10964-008-9389-1

Bloomberg, L. D., \& Volpe, M. (2012). Completing your qualitative dissertation: A road map from beginning to end. Thousand Oaks, CA: Sage.

Callaghan, T. D. (2009). The historical, philosophical and sociological foundations that contribute to the institutionalization of homophobia in Canadian Catholic schools. In J. Nahachewsky \& I. Johnston (Eds.), Beyond presentism: Re-imagining the historical, personal, and social places of curriculum (pp. 61-72). Rotterdam, The Netherlands: Sense.

Callaghan, T. D. (2016). Religiosity. In E. Brockenbrouh, J. Ingrey, W. Martino, \& N. M. Rodriguez (Eds.), Critical concepts in queer studies and education: An international guide for the twenty-first century, (pp. 223 - 230). New York, NY: Palgrave Macmillan.

Canadian Psychological Association. (2017). Canadian code of ethics for psychologists ( $4^{\text {th }}$ ed.). Retrieved from https://www.ccpa-accp.ca/wp-content/uploads/2014/10/CodeofEthics_en.pdf

Castro, I., \& Sujak, M. (2014). "Why can't we learn about this?” Sexual minority students navigate the official and hidden curricular spaces of high school. Education and Urban Society, 46(4), 450-473. http://dx.doi.org/10.1177/0013124512458117

Charmaz, K. (2000). Grounded theory: Objectivist and constructivist methods. In N. Denzin \& Y. Lincoln (Eds.), Handbook of qualitative research (2nd ed.) (pp. 509-536). Thousand Oaks, CA: Sage.

Clandinin, D. J., \& Connelly, F. M. (2000). Narrative inquiry: Experience and story in qualitative research. San Francisco, CA: Jossey-Bass.

Clandinin, D. J., \& Rosiek, J. (2007). Mapping a landscape of narrative inquiry: Borderland, spaces, and tensions. In D. Clandinin (Ed.), Handbook of narrative inquiry: Mapping a methodology (pp. 35-76). Thousand Oaks, CA: Sage.

Clemens, C. (2017, June 5). Ally or accomplice? The language of activism. Teaching Tolerance. Retrieved from: https://www.tolerance.org/magazine/ally-or-accomplice-the-language-of-activism

Cohen, L., Manion, L., \& Morrison, K. (2011). Research methods in education ( $7^{\text {th }}$ ed.). New York, NY: Routledge.

Crowell, K. A., Galliher, R. V., Dehlin, J., \& Bradshaw, W. S. (2015). Specific aspects of 
minority stress associated with depression among LDS affiliated non-heterosexual adults. Journal of Homosexuality, 62(2), 242-267. http://dx.doi.org/10.1080/00918369.2014.969611

Depoian, C. (2009). Homosexuality, the public school curriculum, and the first amendment: Issues of religion and speech. Law \& Sexuality: A review of Lesbian, Gay, Bisexual, \& Transgender Legal Issues, 18, 163-181.

Dykes, F. O., \& Delport, J. L. (2018). Our voices count: The lived experiences of LGBTQ educators and its impact on teacher education preparation programs. Teaching Education, 29(2), 135-146. http://dx.doi.org/10.1080/10476210.2017.1366976

Fredman, A., Schultz, N., \& Hoffman, M. (2015). "You're moving a frickin' big ship": The challenges of addressing LGBTQ topics in public schools. Education and Urban Society, 47(1), 56-85. http://dx.doi.org/10.1177/0013124513496457

Friend, R. (1993). Choices, not closets: Heterosexism and homophobia in schools. In L. Weis \& M. Fine (Eds.), Beyond silenced voices: Class, race, and gender in U.S. schools (pp. 209-235). Albany, NY: State University of New York Press.

Ghiso, M. P., Campano, G., \& Hall, T. (2012). Braided histories and experiences in literature for children and adolescents. Journal of Children's Literature, 38(2), 14-22.

Grace, A. P. (2006). Writing the queer self: Using autobiography to mediate inclusive teacher education in Canada. Teaching and Teacher Education, 22(7), 826-834. http://dx.doi.org/ 10.1016/j.tate.2006.04.026

Huncar, A. (2016, November 1st). Should drag shows be used as a teaching tool in Alberta schools? CBC News. Retrieved from https:/www.cbc.ca/news/canada/edmonton/shoulddrag-shows-be-used-as-a-teaching-tool-in-alberta-schools- 1.3830417

Josselson, R. (2013). Interviewing for qualitative inquiry: A relational approach. New York, NY: Guilford Press.

Kim, J. H. (2016). Understanding narrative inquiry. Thousand Oaks, CA: Sage.

Kosciw, J., Greytak, E., \& Bartkiewicz, M. (2014). Failing progress: Changes in school climate for LGBT youth over time. In E. Meyer \& D. Carlson (Eds.), Gender and sexualities in education: A reader (pp. 188-201). New York, NY: Peter Lang.

Kosciw, J., Greytak, E., Diaz, E., \& Bartkiewicz, M. (2010). The 2009 National School Climate Survey: The experiences of lesbian, gay, bisexual, and transgender youth in our nation's schools. New York, NY: Gay, Lesbian, and Straight Education Network. Retrieved from http://www.glsen.org/content/2009-national-school-climate-survey-fullreport

Leonardi, B., \& Saenz, P. (2014). Conceptualizing safety from the inside out: Heteronormative spaces and their effects on students' sense of self. In E. Meyer \& D. Carlson (Eds.), Gender and sexualities in education: A reader (pp. 202-216). New York, NY: Peter Lang.

Lincoln, Y., \& Guba, E. (1985). Naturalistic inquiry. Newbury Park, CA: Sage.

Macgillivray, I. K. (2000). Educational equity for gay, lesbian, bisexual, transgendered, and queer/questioning students: The demands of democracy and social justice for America's schools. Education and Urban Society, 32(3), 303-323. http://dx.doi.org/10.1177/0013124500323003

Macintosh, L. (2007). Does anyone have a band-aid? Anti-homophobia discourses and pedagogical impossibilities. Educational Studies, 41(1), 33-43. http://dx.doi.org/10.1080/00131940701308874

Journal of Contemporary Issues in Education, 2019, 14(2), pp. 33-49. 
Maxwell, J. A. (1997). Designing a qualitative study. In L. Bickman \& D. J. Rog (Eds.), Handbook of applied social research methods (pp. 69 - 100). Thousand Oaks, CA: Sage.

Maxwell, J. A. (2005). Qualitative research design: An interactive approach (2 $\left.{ }^{\text {nd }} \mathrm{ed}.\right)$. Thousand Oaks, CA: Sage.

Merriam, S. B. (2002). Qualitative research in practice: Examples for discussion and analysis. New York, NY: Jossey-Bass.

Meyer, I. H. (2003). Prejudice, social stress, and mental health in lesbian, gay, and bisexual populations: Conceptual issues and research evidence. Psychological Bulletin, 129(5), 674-697. http://dx.doi.org/10.1037/0033-2909.129.5.674

Meyer, E. J. (2009). Gender, bullying, and harassment: Strategies to end sexism and homophobia in schools. New York, NY: Teachers College Press.

Meyer, E. J., Taylor, C., \& Peter, T. (2015). Perspectives on gender and sexual diversity (GSD)inclusive education: comparisons between gay/ lesbian/bisexual and straight educators. Sex Education: Sexuality, Society, and Learning, 15(3), 221-234. http://dx.doi.org/ 10.1080/14681811.2014.979341

Miller, S. J., \& Gilligan, J. R. (2014). Heteronormative harassment: Queer bullying and gender non-conforming students. In E. Meyer \& D. Carlson (Eds.), Gender and sexualities in education: A reader (pp. 217-229). New York, NY: Peter Lang.

Murphy, R. (2016, October 28). Rex Murphy: Jordan Peterson-A real professor, at last. National Post. Retrieved from https://nationalpost.com/opinion/rex-murphy-jordan-peterson-areal-professor-at-last

Nunn, L. M., \& Bolt, S. C. (2015). Wearing a rainbow bumper sticker: Experiential learning on homophobia, heteronormativity, and heterosexual privilege. Journal of LGBT Youth, 12(3), 276-301. http://dx.doi.org/10.1080/19361653.2015.1045963

Owen, W. F. (1984). Interpretive themes in relational communication. Quarterly Journal of Speech, 70, 274-287. http://dx.doi.org/10.1080/00335638409383697

Polkinghorne, D. E. (1995). Narrative configuration as qualitative analysis. In J.A. Hatch \& R. Wisniewski (Eds.), Life history and narrative (pp. 5-25). London, UK: Falmer Press.

Puchner, L., \& Klein, N. (2011). The right time and place? Middle school Language Arts teachers talk about not talking about sexual orientation. Equity and Excellence in Education, 44(2), 223-248. http://dx.doi.org/10.1080/10665684.2011.563182

Robinson, K. H., \& Ferfolja, T. (2002). A reflection of resistance: Discourses of heterosexism and homophobia in teacher training classrooms. Journal of Gay \& Lesbian Social Services, 14(2), 55-64. http://dx.doi.org/10.1300/J041v14n02_05

Sieben, N., \& Wallowitz, L. (2009). "Watch what you teach": A first year teacher refuses to play it safe. English Journal, 98(4), 44-49. Retrieved from http://www.jstor.org/stable/40503260

Suldo, S.M., Friedrich, A.A., White, T., Farmer, J., Minch, D., \& Michalowski, J. (2009). Teacher support and adolescents' subjective well-being: A mixed-methods investigation. School Psychology Review, 38(1), 67-85.

Swearer, S. M., Turner, R. K., Givens, J. E., \& Pollack, W. S. (2008). 'You're so gay!': Do different forms of bullying matter for adolescent males? School Psychology Review, 37(2), 221-227.

Taylor, C., \& Peter, T., with McMinn, T.L., Elliott, T., Beldom, S., Ferry, A., Gross, Z., Paquin, S., \& Schachter, K. (2011). Every class in every school: The first national climate survey on homophobia, biphobia, and transphobia in Canadian schools. Final

Journal of Contemporary Issues in Education, 2019, 14(2), pp. 33-49. 
report. Toronto, ON: Egale Canada Human Rights Trust. Retrieved from http://egale.ca/wp-content/uploads/2011/05/EgaleFinalReport-web.pdf

Zimmerman, J. (2015). Too hot to handle: A global history of sex education. Princeton, NJ: Princeton University Press. 